\title{
Museum collections reveal that Buff-breasted Sandpipers (Calidris subruficollis) maintained mtDNA variability despite large population declines during the past 135 years
}

\author{
Zachary T. Lounsberry $\cdot$ Juliana B. Almeida $\cdot$ Richard B. Lanctot • \\ Joseph R. Liebezeit • Brett K. Sandercock • Khara M. Strum • \\ Steve Zack $\cdot$ Samantha M. Wisely
}

Received: 19 July 2013/Accepted: 15 April 2014/Published online: 1 May 2014

(C) The Author(s) 2014. This article is published with open access at Springerlink.com

\begin{abstract}
A principal goal of conservation efforts for threatened and endangered taxa is maintenance of genetic diversity. Modern and historic processes that limit population size can contribute to a loss of genetic variation that can reduce future adaptability of a species. Buff-breasted Sandpipers (Calidris subruficollis) are a Neotropical migratory shorebird that experienced rapid, large-scale declines in population numbers (population bottleneck) due
\end{abstract}

Z. T. Lounsberry · B. K. Sandercock · K. M. Strum

Division of Biology, Kansas State University, 116 Ackert Hall, Manhattan, KS 66506, USA

Present Address:

Z. T. Lounsberry

Department of Veterinary Genetics, University of California,

One Shields Ave/Old Davis Road, Davis, CA 95616, USA

J. B. Almeida

Ecology Evolution and Conservation Biology Program/MS 314,

University of Nevada, Reno, NV 89557, USA

R. B. Lanctot

US Fish and Wildlife Service, Migratory Bird Management, 1011 East Tudor Road, MS 201, Anchorage, AK 99503, USA

J. R. Liebezeit · S. Zack

Wildlife Conservation Society, Pacific West Office, 718 SW

Alder Street, Suite 210, Portland, OR 97205, USA

Present Address:

K. M. Strum

Point Blue Conservation Science, 3820 Cypress Drive, Suite 11, Petaluma, CA 94954, USA

S. M. Wisely $(\square)$

Department of Wildlife Ecology and Conservation, University of Florida, Gainesville, FL 32611, USA

e-mail: wisely@ufl.edu to intensive market hunting at the turn of the 20th century. Market hunting ended shortly after the passage of the Migratory Bird Treaty Act in 1918, but subsequent population losses have occurred due to continued anthropogenic disturbances throughout the species' migratory range. To assess the impact of population declines on the genetic variation of Buff-breasted Sandpipers, we surveyed two mitochondrial DNA (mtDNA) markers, the control region and cytochrome $b$, from 209 museum specimens collected between 1874 and 1983 and 460 modern samples collected between 1993 and 2009. Measures of mtDNA variation did not change significantly among individuals sampled before and after the ban on market hunting, nor among four temporal groups (Pre-Act, Early Post-Act, Late Post-Act, and Modern; trend analysis: $\chi^{2}=0.171, P=0.679$ ). Similarly, we did not observe loss of common haplotypes, implying that there was no substantial reduction in unique matrilineal units during our 135-year study period. Using Bayesian Skyline reconstruction of temporal changes in effective population size of females $\left(N_{\mathrm{ef}}\right)$, we concluded that $N_{\text {ef }}$ has been stable for the past century. Results of resampling suggest that diversity estimators can be imprecise and we emphasize the importance of a wellrounded analytical approach to addressing conservation genetic hypotheses. Considering all of the evidence it appears that genetic variation and $N_{\text {ef }}$ were stable despite the pressures of market hunting early in the 20th century and habitat loss and degradation in the latter half of the 20th century. Conservation efforts should continue to focus on maintaining the population size of Buff-breasted Sandpipers to avoid reaching a threshold where genetic variability is lost.

Keywords Effective population size - Historic DNA . mtDNA $\cdot$ Shorebird $\cdot$ Wader 


\section{Introduction}

Maintenance of genetic variation is a central objective of conservation efforts for a wide diversity of threatened taxa (Spielman et al. 2004). This key management goal is based on the principle that populations with greater genetic variation are more resilient to environmental stochasticity and the deleterious effects of inbreeding (Soulé 1991; Brook et al. 2002; Frankham 2005). Events in the past, either natural such as climate-induced range contraction or anthropogenic such as habitat loss, can reduce population size and erode genetic variation, which has the potential to reduce fitness (Frankham et al. 2004). In order to better understand the vulnerability of imperiled taxa to these genetic forces, the impact of past events needs to be elucidated.

Often, the impacts of historic processes are inferred from genetic characteristics of contemporary populations. Historic DNA (hereafter, hDNA) isolated from museum specimens allows conservation geneticists to examine effects of historic events directly instead of relying on inference from study of contemporary specimens (Ramakrishnan and Hadly 2009). If low genetic diversity is the result of recent population declines, contemporary sampling may underestimate the loss of unique alleles or lineages not observed in contemporary samples (Johnson et al. 2007), and researchers might misinterpret the impact of population declines on their study system. Using historic samples allows conservation geneticists to elucidate finescale population trends, and thus hDNA can provide a historical perspective on large-scale population declines that may not be apparent from contemporary sampling alone (Wandeler et al. 2007; Mourier et al. 2012). Furthermore, museum collections allow for robust sampling of hDNA over long time periods, allowing the assessment of long-term changes in population size on genetic variation.

Many species of migratory shorebirds (Aves: Charadriiformes) have experienced major population declines during the past 150 years (Andres et al. 2012). Initially, largescale declines in North America were associated with intensive market hunting of migratory birds in the late 1800's (Sutherland et al. 2012) resulting in population bottlenecks for many migratory shorebirds at the turn of the last century. Some of the species negatively affected were the American Golden-Plover (Pluvialis dominica, Clay et al. 2010), American Oystercatcher (Haematopus palliatus, George 2002), Buff-breasted Sandpiper (Calidris subruficollis, Lanctot and Laredo 1994), Long-billed Curlew (Numenius americanus, Allen 1980), Eskimo Curlew (N. borealis, Roberts et al. 2009; Graves 2010), and the American Woodcock (Scolopax minor, Weik 2001). With the enactment of the Migratory Bird Treaty Act in 1918 and legislation passed in the 1920s in South America
(Wetmore 1927), commercial harvest was slowed and eventually halted for most species. Estimates of population size indicate that some species stabilized during the period following the ban on market hunting, but the genetic effects of large-scale harvest of migratory shorebirds remain unclear (Burleigh 1958; Tudor 2000). To date, no studies have used hDNA to investigate the impacts of large-scale population losses on genetic variation in any species of shorebirds.

Population pressures on migratory shorebirds have shifted over the past century from a population bottleneck due to market hunting to more gradual declines due to loss or alteration of suitable habitat, exposure to environmental contaminants, climate change, and other anthropogenic disturbances (Butler et al. 2004; Morrison et al. 2006; Andres et al. 2012; Sutherland et al. 2012). Population losses and the concomitant loss of genetic variation associated with these slow but sustained pressures over multiple generations have been linked to inbreeding depression and negative impacts on adaptability and fitness. Assessing the genetic effects of gradual declines is crucial to the management of shorebirds and other wildlife populations (Westemeier et al. 1998).

The Buff-breasted Sandpiper (C. subrifucollis) is a Neotropical migrant that breeds along the Arctic coasts of Russia, Alaska, and Canada; migrates primarily through the central portion of North and South America; and winters in the grasslands of southeastern South America (Lanctot et al. 2010). Birds have a broad longitudinal distribution during the breeding and nonbreeding season, but concentrate along the Central Flyway during spring and fall migration in places like the Rainwater Basin of southcentral Nebraska and coastal areas of Texas and Louisiana (Lanctot and Laredo 1994; Jorgensen et al. 2008; Norling et al. 2012). Like other shorebirds, this historically abundant species underwent substantial population declines in the past 150 years. A pulsed, rapid decline of Buff-breasted Sandpipers resulting in a population bottleneck was largely attributed to market hunting in the late 1800's and early 1900's (Rowan 1927; McIlhenny 1943; Myers 1980), with pre-exploitation estimates of Buff-breasted Sandpipers ranging into the hundreds of thousands of birds (Lanctot et al. 2010). Subsequent to the ban on market hunting, anthropogenic disturbances along migratory routes, including the loss of grassland habitat and exposure to toxic environmental contaminants, likely resulted in less dramatic but steady population losses (Lanctot et al. 2010; Strum et al. 2010). Contemporary estimates of global population size for Buff-breasted Sandpipers range from 15,000 to 84,000 birds. Limited trend data available suggest the species has continued to decline in recent decades (Lanctot et al. 2010; Andres et al. 2012), although new results from grassland surveys at 11 locations in three 
countries in South America suggest the population size was stable between 2008 and 2011 (Southern Cone Grasslands Alliance, unpublished data).

The population dynamics of Buff-breasted Sandpipers over the past 150 years provide a unique opportunity to empirically assess temporal changes in genetic characteristics during a known population bottleneck and followed by nearly a century of gradual population declines. The goal of our study was to estimate the impact of rapid and gradual changes in population size on mitochondrial DNA (mtDNA) variation in Buff-breasted Sandpipers. We chose to use mtDNA markers to address the timing of population decline and loss of unique lineages. Analyses of contemporary populations with nuclear markers did not find evidence of a genetic signal associated with a population decline nor did they reveal any sex-biased population structure (Lounsberry et al. 2013). We chose not to use nuclear markers such as microsatellites due to the age of specimens and quality and quantity of DNA, which can result in high genotyping error rates and underestimates (due to allelic dropout) or, less frequently, overestimates (due to false alleles) of historic allelic variation (Wandeler et al. 2007; Millar et al. 2008). Previous studies have successfully used mitochondrial markers in hDNA samples to reveal declines in genetic diversity over time in several species of birds (Martinez-Cruz et al. 2007; Solovyeva and Pearce 2011; Draheim et al. 2012). We sought to evaluate changes in mtDNA variation and female effective population size $\left(N_{\mathrm{ef}}\right)$, as well as the possible extirpation of unique matrilineal units. We predicted that mtDNA variation and $N_{\text {ef }}$ would be greater before the large-scale market hunting of Buff-breasted Sandpipers than in the decades following the cessation of hunting. We also predicted an ongoing decay in genetic variation as Buff-breasted Sandpiper populations continued to decline during the 20th century.

\section{Methods}

\section{Sampling and DNA extraction}

We obtained a total of 209 Buff-breasted Sandpiper tissue samples from either shafts of contour flank feathers or toe pad shavings from ten collections at natural history museums in the U.S. We compared historical samples to 460 modern samples. Historical samples represented birds collected from 1841 to 1983 across the species' distributional range (Fig. 1, Online Resource 1). To assess temporal changes in genetic variation, we binned individuals into four temporal groups prior to laboratory analysis. Groups were defined relative to the timing of the passage of the Migratory Bird Treaty Act, the event that signaled the end of the initial population bottleneck. These groups included (1) Pre-Act (1874-1919, $n=80)$, (2) Early PostAct (1920-1959, $n=62)$, (3) Late Post-Act (1960-1983, $n=67$ ), and (4) Modern (1993-2009, $n=460)$; the number of samples for which we obtained sequence was smaller (see "Results" section). Early Post-Act represents the period of time prior to the widespread use of pesticides and industrialized agriculture, while Late Post-Act and Modern represent time periods marked by increasing industrialization of agriculture and loss of habitat.

In addition to temporal variation in sampling, our museum specimen locations were likely representative of animals throughout their breeding and wintering range (Fig. 1), because the location of our museum specimens overlapped with the current distribution of the species. This assumes, however, that there has been no major range shift over the past century. (Fig. 1, Online Resource 1). In addition, a large proportion of the historic samples were collected in the Central Flyway of North America, which is the principal migratory route used by the species to migrate between the breeding and wintering grounds; thus, samples from the Central Flyway should be representative of the global population (Lanctot et al. 2010). Population genetic studies of contemporary Buff-breasted Sandpipers support this observation; genetic variation of groups collected in the flyway did not differ from breeding or wintering groups and the species was characterized as one globally admixed population (Lounsberry et al. 2013). Using a combination of mtDNA and microsatellite markers, Lounsberry et al. (2013) found no genetic structure within breeding or wintering grounds nor among breeding, wintering and stopover sites. Thus, for purposes of analysis in this study of museum specimens, we assumed admixture across sampling locations and defined analytical groups solely by collection date.

We extracted DNA from all tissue samples using phenol-chloroform extraction procedures modified from Wisely et al. (2004). Depending on the type of tissue received for each museum specimen, we extracted one to three feather shafts or one toe pad per individual. All samples were chopped finely with a clean razorblade and incubated overnight in lysis buffer before starting the phenol-chloroform extraction. We eluted extracted DNA to $150 \mu \mathrm{l}$ in sterile water and stored it in the laboratory at $-20{ }^{\circ} \mathrm{C}$.

To minimize possible contamination of hDNA samples, we performed all extractions in a genetics laboratory dedicated to handling of historic samples. We bleached counter surfaces and equipment using a $10 \%$ bleach solution before and after every extraction to reduce risk of contamination. Every set of twelve extractions contained one or more negative controls that followed the entire tissue extraction procedure but used a water blank instead of a 
Fig. 1 Locations where museum specimen and modern Buff-breasted Sandpiper samples were obtained. Groups include Pre-Act (1874-1919), Early Post-Act (1920-1959), Late Post-Act (1960-1983), and Modern (1993-2009)

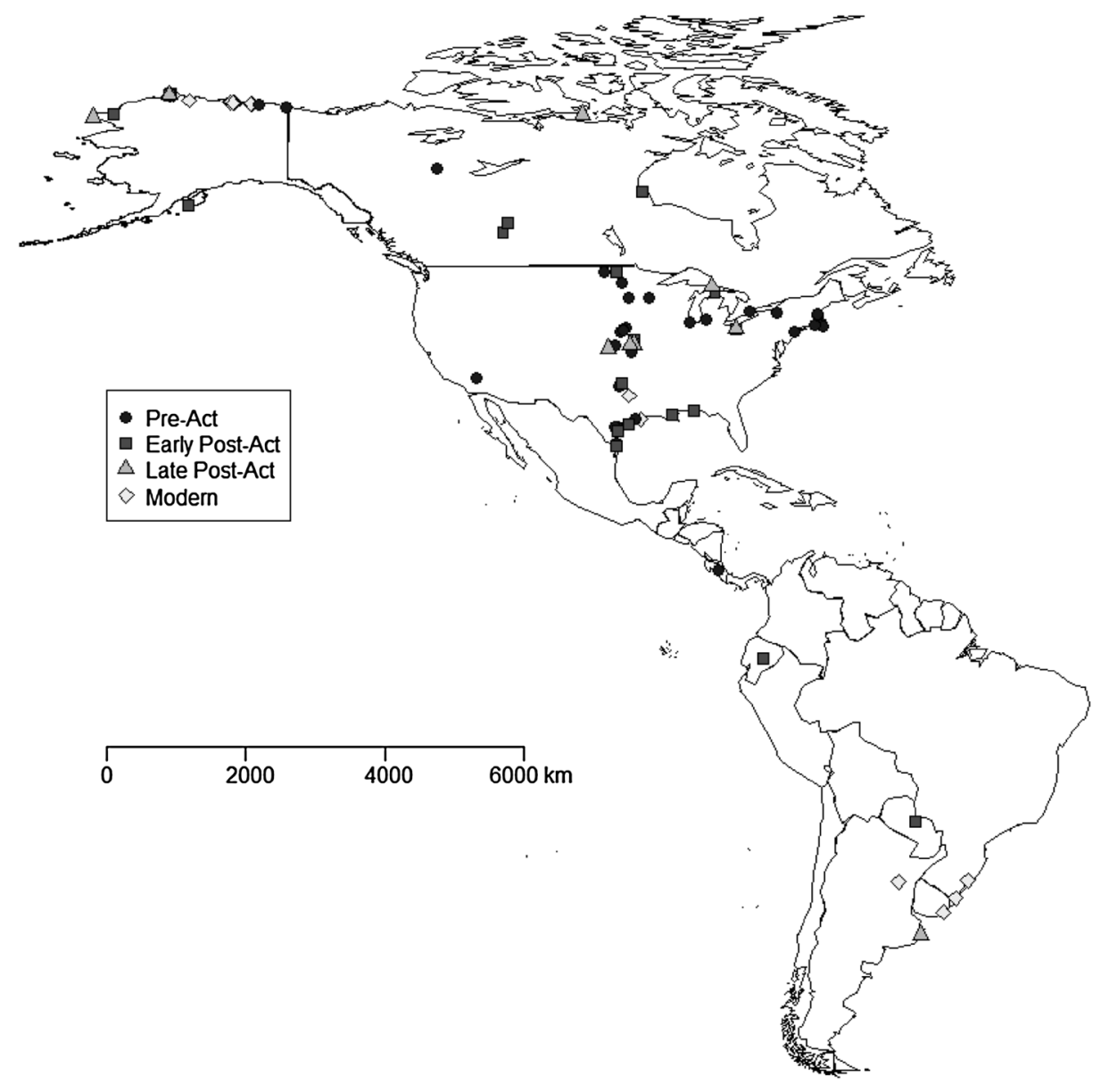

tissue sample. We tested each negative control for contamination via polymerase chain reactions (PCR) amplification. To minimize all possible sources of PCR contamination, personnel entering the laboratory showered prior to entry and wore protective clothing that was kept exclusively in the laboratory.

\section{DNA amplification and sequencing}

We amplified DNA samples by PCR using novel primers developed for this project (Online Resource 2). Since hDNA is typically highly fragmented, we designed novel primers to amplify two short (approx. $250 \mathrm{bp}$ each), overlapping segments within the mtDNA control region, and four segments within the cytochrome $b$ gene. Prior to processing museum specimens, we optimized primer conditions using DNA extracted from blood samples collected from Buff-breasted Sandpipers in the past two decades (hereafter, modern samples; Lounsberry et al. 2013). Once primers were optimized, we ordered primer oligonucleotides to be used exclusively in the hDNA lab to avoid possible contamination from the molecular laboratory that housed modern samples.
We amplified DNA from museum specimens in PCR mixtures at a volume of $25 \mu \mathrm{l}$ containing $2 \mu \mathrm{l}$ template DNA in final elution, $5 \mu \mathrm{l} 1 \times$ reaction buffer $\left(\mathrm{MgCl}_{2}\right.$ included; Thermo Scientific), $0.2 \mathrm{mM}$ of each dNTP, $0.5 \mu \mathrm{M}$ of each forward and reverse primer (Online Resource 2), $2.5 \mu \mathrm{g}$ bovine serum albumen (BSA), and $0.1 \mathrm{U}$ of Phire Hot Start II DNA polymerase (Thermo Scientific). Thermal profiles consisted of one $30 \mathrm{~s}$ denaturation step at $98{ }^{\circ} \mathrm{C}$ followed by 35 cycles combining a $5 \mathrm{~s}$ denaturation step at $98{ }^{\circ} \mathrm{C}$, a $5 \mathrm{~s}$ annealing step at $50{ }^{\circ} \mathrm{C}$, and a $10 \mathrm{~s}$ extension at $72{ }^{\circ} \mathrm{C}$, and a final extension step for $1 \mathrm{~min}$ at $72{ }^{\circ} \mathrm{C}$. We sequenced PCR products in both directions at University of Kentucky AGTC Sequencing Center via BigDye reactions with the same forward and reverse primers used for amplification.

We assessed chromatographs by eye for errors in the resulting forward and reverse sequences and then compiled the information into consensus sequences in Bioedit version 7.0.5.3 (Hall 1999). We aligned consensus sequences visually in MEGA4 (Tamura et al. 2007). We then assembled both segments of the control region and three of the four segments of cytochrome $b$, respectively, for analyses. Because of the low quality of hDNA, we were not 
successful in amplifying our full target cytochrome $b$ segment for all museum specimens. Thus, we conducted cytochrome $b$ analyses solely on individuals that successfully amplified at three of the four segments, CytB2CytB4. We archived sequences representing each of the haplotypes recovered from museum specimens with voucher information in Genbank (Accession Numbers JX123379-JX123419).

\section{MtDNA variation}

For temporal comparisons, we supplemented our hDNA sequence database with modern samples of sandpipers analyzed by Lounsberry et al. (2013). Modern samples were obtained from live Buff-breasted Sandpipers captured at breeding, migration, and wintering sites after 1992 . Before conducting phylogenetic analyses, we trimmed modern sequences to cover the same segments amplified from the hDNA obtained from museum samples. We translated hDNA cytochrome $b$ sequences from nucleotide to amino acid sequences in MEGA4 to confirm that sequences were fully coding, had no frameshift mutations or premature stop codons, and showed no evidence of nuclear pseudogene amplification (Rodríguez et al. 2007). We resequenced a small subset $(10 \%, 20$ individuals) of individuals to confirm sequence identity.

We also compared individuals collected before (pre1920) and after (1920-2009) the end of commercial harvest. To assess possible losses of unique matrilines over our study period, we used the Tempnet package in $\mathrm{R}$ version 2.12 .2 to construct a statistical parsimony network for all four temporal groups (R Development Core Team 2010; Prost and Anderson 2011). Because the most common haplotype was found in $>50 \%$ of individuals, we also assessed changes in haplotype distribution by using the relationship between Snedecor's $F$ distribution and a binomial distribution to assign $95 \%$ confidence intervals to the proportion of individuals with the most common haplotypes in each temporal group (Zar 1984). We also calculated standard molecular diversity indices including number of haplotypes $(h), H_{\mathrm{d}}$, and nucleotide diversity $(\pi)$ for both mtDNA regions for all temporal groups, as well as pre- and post- Act groups, in DnaSP version 5 (Librado and Rosaz 2009). We estimated $\Phi$ statistics from analyses of molecular variance (AMOVA) among temporal groups to determine a signal of population differentiation between time points using 1,000 permutations in Arlequin version 3.5 (Excoffier et al. 2005). To test for potential declines in the number of haplotypes over time, we calculated the ratio of unique haplotypes to individuals $(h / N)$ for all temporal groups and performed a
Cochran-Armitage test for trend on the proportions in $\mathrm{R}$ (Armitage 1955). Specifically, this modified Pearson $\chi^{2}$ test generalizes a two-sample $Z$ test to check for a linear trend (i.e., increasing or decreasing) in frequencies of proportions among multiple categorical groups. In this case, the null hypothesis is that there is no linear trend between temporal groups and the number of haplotypes per individual. A significant $\chi^{2}$ test statistic supports the hypothesis of a trend in proportions over time. To account for differences in sample sizes among hDNA temporal groups when estimating the number of haplotypes, we conducted a rarefaction correction for the number of haplotypes expected from a larger group of samples in EstimateS version 8.2.0 (Colwell 2009). Specifically, we combined all haplotypes from our entire sequence dataset to predict the number of haplotypes that would be expected in each temporal group based on the rarefaction curve plotted from a sample that was a full order of magnitude larger $(n=669)$ than our hDNA temporal groups (average $n=50$ ).

Sample size and diversity indices

We obtained a larger sample size than is typical of conservation-focused hDNA studies for shorebirds from museum specimens (e.g., $n=49$ in Draheim et al. 2012 and $n=209$ in present study), but still smaller than the contemporary samples $(n=460)$. A large sample size was critical to our study, because of the low diversity of haplotypes in the modern population (Lounsberry et al. 2013). To be confident that we were sampling an adequate number of individuals to overcome this limitation, we needed to sample a larger-than-average number of historic specimens. To determine whether the sample size of the historic temporal groups did not bias estimates of haplotype diversity $\left(H_{\mathrm{d}}\right)$, we performed a series of 500 random resampling iterations with replacement from our large modern sequence dataset (control region $n=460$ and cytochrome $b n=438$ sequences) at adjusted sample sizes to assess the impact of sample size on $H_{\mathrm{d}}$. We used the variance from the 500 estimates at each sample size to assign $95 \%$ confidence intervals. For temporal comparisons, we used a value of $H_{\mathrm{d}}$ adjusted to the mean sample size of museum temporal groups (control region $n=48$ and cytochrome $b n=51$ ).

\section{Demographic reconstruction}

To empirically test for demographic trends in mtDNA variation over our study period, we used several methods of temporal demographic reconstruction. To assess 
changes in female effective population size, we estimated Watterson's $\theta\left(\theta_{\mathrm{w}}\right)$ to use as a proxy for $N_{\mathrm{ef}}$ in DnaSP. Since mtDNA is maternally inherited, effective population size estimates derived from mtDNA haplotype data are expressed in numbers of breeding females by: $\theta=2 N e f \mu$, where $N_{\text {ef }}$ is the effective population size of females, and $\mu$ is the mutation rate per site per generation. However, $\theta$ has been shown to yield inflated estimates of historical effective population size, so we chose solely to interpret our patterns of changing $\theta$ over time as a proxy for $N_{\mathrm{ef}}$ rather than calculating the values themselves (Palsbøll et al. 2013). To verify our estimates, we used cytochrome $b$ sequences from samples with known tip dates to visualize fluctuations in $N_{\text {ef }}$ graphically. Using tip-dated sequences allowed us to look at recent changes in $N_{\text {ef }}$ with greater resolution. To choose the best-fit nucleotide mutation model, we used model selection based on Akaike's information criterion (AIC) in jModelTest version 3.7 (Posada 2008). We then estimated changes in population size over time performing $10^{7}$ iterations (discarding the first $10^{6}$ as burn-in) of MCMC simulations, and by imposing a Bayesian skyline plot as our demographic model in BEAST version 1.6.2 (Drummond and Rambaut 2007).

(a)

Resampled Hd Distributions - Control region

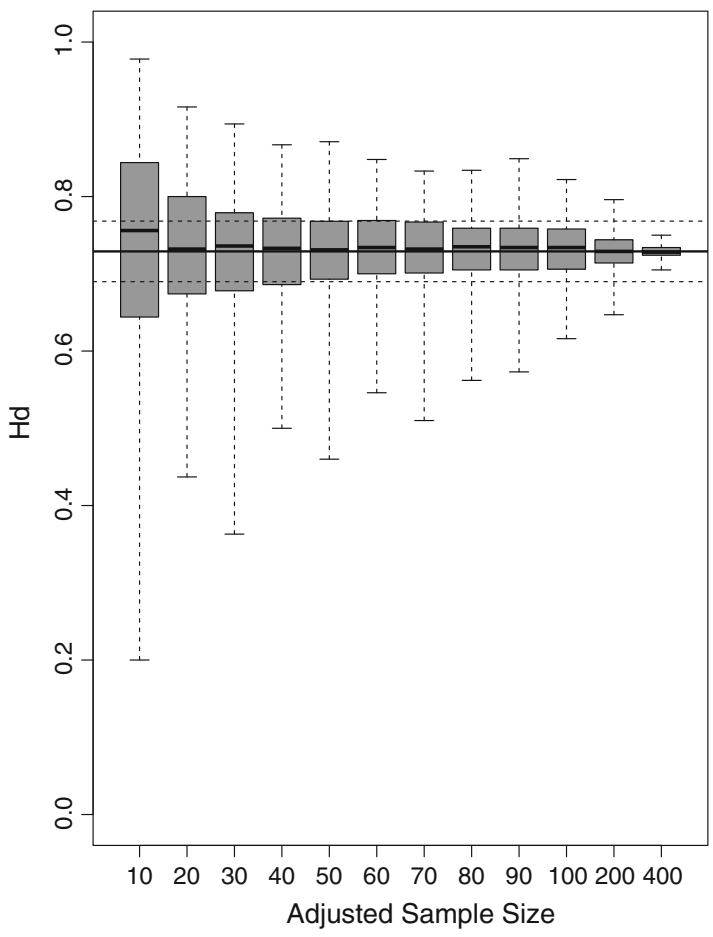

Fig. 2 Boxplots representing means and quantiles of $H_{\mathrm{d}}$ point estimates for 500 iterations of random resampling with replacement of the modern sample at various sample sizes. Solid lines represent $H_{\mathrm{d}}$

\section{Results}

Sample size and diversity indices

Resampling iterations revealed that even at large sample sizes $(n=200), H_{\mathrm{d}}$ was sensitive to which individuals were randomly sampled from the global population of Buff-breasted Sandpipers. While mean estimates of $H_{\mathrm{d}}$ were similar from small to large sample sizes, variation in point estimates remained large, making estimates derived from small sample sizes unreliable to interpret (Fig. 2).

\section{MtDNA variation}

We obtained the entire sequence for the $335 \mathrm{bp}$ segment of the mtDNA control region in 152 of 219 (69\%) hDNA samples. We were able to successfully amplify sequence from 46 Pre-Act samples, 51 Early Post-Act samples, and 56 Late Post-Act samples. We observed 24 unique haplotypes, eight of which were not present among our modern samples for Buff-breasted Sandpipers (Online Resource 1). Among all temporal groups, the most common haplotype (CRM1) and second most common haplotype (CRM2)

(b) Resampled Hd Distributions - Cytochrome b

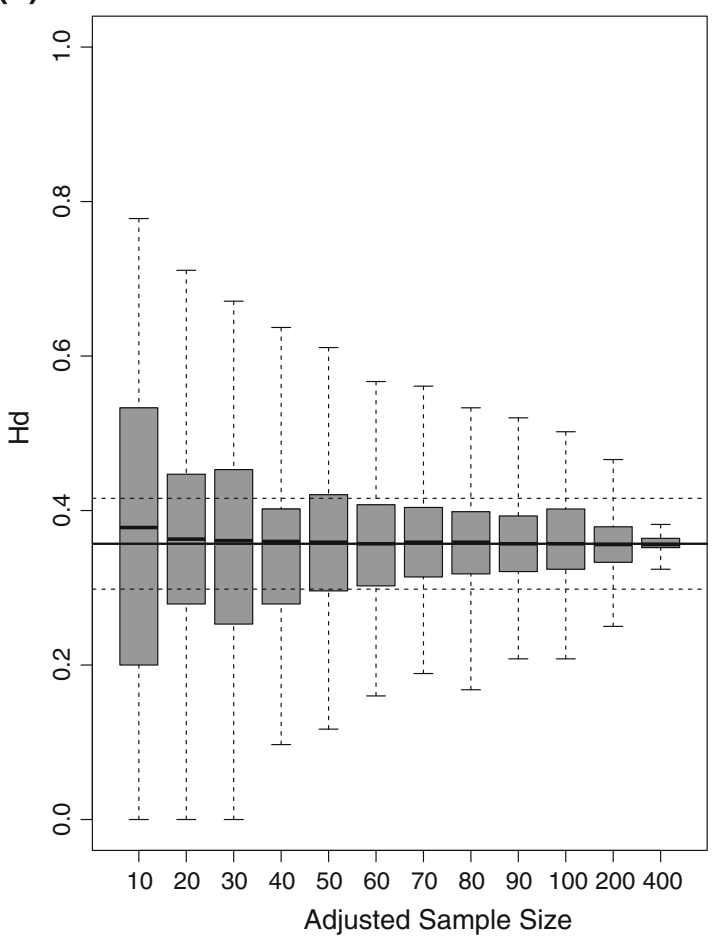

in the modern group and dotted lines represent their respective $95 \%$ CI. Figure $3 \mathrm{a}$ is a resampling effort for the control region. Figure $3 \mathrm{~b}$ represents resampling for cytochrome $b$ 
Table 1 Molecular diversity indices for the mtDNA control region and cytochrome $b$ gene within Buff-breasted Sandpipers sampled before and after the Migratory Bird Treaty Act in 1918

\begin{tabular}{llllllll}
\hline Temporal groups & $N$ & $H_{d}$ & $\pi \times 10^{3}$ & $h$ & $A$ & $h / N$ & $95 \% \mathrm{CI}$ \\
\hline Control region & & & & & & & \\
$1847-1919$ & 41 & $0.669 \pm 0.071$ & $3.40 \pm 0.660$ & 10 & $28.0 \pm 15.1$ & 0.244 & $(0.397,0.715)$ \\
$1920-1959$ & 49 & $0.713 \pm 0.059$ & $3.25 \pm 0.500$ & 13 & $44.0 \pm 23.3$ & 0.245 & $(0.363,0.656)$ \\
$1960-1983$ & 53 & $0.708 \pm 0.058$ & $4.16 \pm 0.760$ & 13 & $64.0 \pm 32.6$ & 0.264 & $(0.423,0.703)$ \\
$1993-2009$ & 48 & $0.733 \pm 0.060$ & $4.01 \pm 0.694$ & 14 & $45.4 \pm 20.1$ & 0.292 & $(0.340,0.637)$ \\
Cytochrome $b$ & & & & & & \\
$1847-1919$ & 46 & $0.416 \pm 0.092$ & $1.06 \pm 0.280$ & 10 & $33.0 \pm 19.1$ & 0.227 & $(0.661,0.906)$ \\
$1920-1959$ & 51 & $0.322 \pm 0.085$ & $0.630 \pm 0.180$ & 7 & $8.00 \pm 1.90$ & 0.120 & $(0.680,0.912)$ \\
$1960-1983$ & 55 & $0.236 \pm 0.074$ & $0.500 \pm 0.170$ & 5 & $7.00 \pm 3.00$ & 0.091 & $(0.751,0.946)$ \\
$1993-2009$ & 51 & $0.343 \pm 0.083$ & $0.921 \pm 0.239$ & 7.2 & $14.29 \pm 6.05$ & 0.142 & $(0.674,0.906)$ \\
\hline
\end{tabular}

Sample size for the modern group (1993-2009) represents the adjusted sample size for 500 iterations of random resampling

$N$ number of individuals, $H_{d}$ haplotype diversity $\pm \mathrm{SD}, \pi$ nucleotide diversity $\pm \mathrm{SD}, h$ total number of haplotypes, $A$ rarefaction estimate of haplotypes $\pm \mathrm{SD}, h / N$ the proportion of haplotypes to the total number of individuals in the population; $95 \% C I$ confidence intervals around the proportion of the most common haplotype relative to the total sample

averaged $51 \%( \pm 2.0 \%)$ and $19 \%( \pm 2.2 \%)$ of the individuals, respectively. All other haplotypes occurred in $\leq 10 \%$ of the individuals in each temporal group. All unique haplotypes present in hDNA temporal groups were singletons. Conversely, in the modern samples, we detected 34 haplotypes not found in the museum samples. Of the 34 unique haplotypes in the modern samples, 19 were also singletons. We did not observe any substantial shifts in haplotype frequencies over our study period for the mitochondrial control region (Table 1).

Haplotype and nucleotide diversity estimates for the control region remained stable over our study period (Table 1). Pairwise AMOVAs did not indicate significant differentiation between any two temporal groups. Lack of differentiation was consistent for our four temporal groups (pairwise- $\Phi_{\mathrm{ST}}$ were not significantly different than $0 ; P$ for any pairwise comparison $>0.65$ ) and the combined pre- and post-Act samples $\left(\Phi_{\mathrm{ST}}=-0.011, P=0.960\right)$. The proportion of haplotypes to individuals $(h / N)$ was also stable over time (trend analysis: $\chi^{2}=0.171, P=0.679$ ). The observed pattern held even after correcting haplotype proportion estimates for variation in sample size $(A)$ with a rarefaction analysis (Table 1). It is important to note that the standard deviation values for the rarefaction analysis were very large. This is likely due to the presence of one central, common haplotype and many rare haplotypes leading to uncertainty in estimating the true expected number of haplotypes.

For 151 museum specimens successfully sequenced at our 552-bp cytochrome $b$ segment, we observed 14 distinct haplotypes, five of which were not present in our modern population. All five unique haplotypes present in museum specimens were singletons, as were eight of the 13 unique

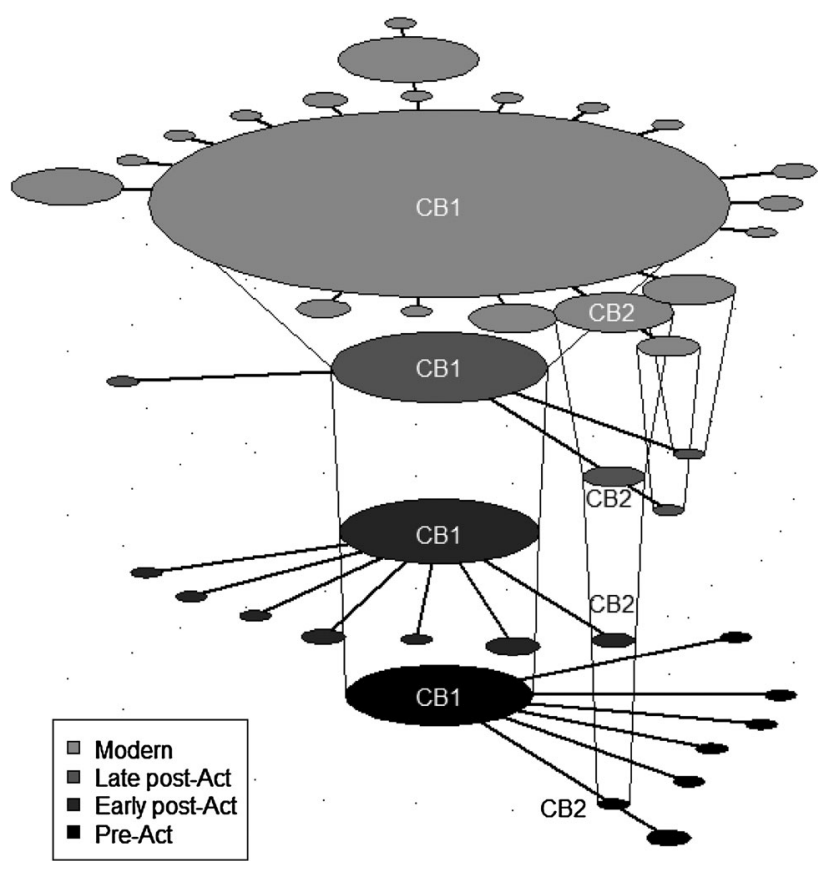

Fig. 3 Haplotype networks for temporal groups showing stable haplotype distributions in cytochrome $b$ over our study period (1874-2009). Each filled node represents a unique haplotype in that temporal group and peripheral dots represent haplotypes found only in other temporal groups. The number of individuals representing a haplotype is proportional to the size of the node. Shared haplotypes between temporal groups are connected with thin lines, and the most common haplotypes (CB1 and CB2) are labeled for reference. Haplotype networks for control region had a similar topology (not shown)

haplotypes in the modern group (Fig. 3). We observed a similar haplotype distribution pattern to that of the control region in cytochrome $b$; with the most common haplotype 
Table 2 Watterson's estimate of $\theta \pm$ SD for the mtDNA control region and cytochrome $b$ across temporal groups showing no major changes in $N_{\text {ef }}$ over time

\begin{tabular}{lll}
\hline Temporal groups & $N$ & $\theta_{\mathrm{w}}$ \\
\hline Control region & & \\
$1847-1919$ & 42 & $2.32 \pm 0.96$ \\
$1920-1959$ & 50 & $2.23 \pm 0.91$ \\
$1960-1983$ & 52 & $3.54 \pm 1.28$ \\
$1993-2009$ & 48 & $2.70 \pm 0.56$ \\
Cytochrome $b$ & & \\
$1847-1919$ & 46 & $2.49 \pm 1.00$ \\
$1920-1959$ & 51 & $1.33 \pm 0.64$ \\
$1960-1983$ & 55 & $0.87 \pm 0.93$ \\
$1993-2009$ & 51 & $1.63 \pm 0.30$ \\
\hline
\end{tabular}

Sample size for the modern group (1993-2009) represents the adjusted sample size for 500 iterations of random resampling

$N$ sample size, $\theta_{w}$ Watterson's estimate of $\theta \pm \mathrm{SD}$

(CBM1) accounting for $82 \%( \pm 3.1 \%)$ of the individuals across all temporal groups (Online Resource 1).

The patterns of haplotype diversity appeared similar between the control region and cytochrome $b$. In cytochrome $b$, diversity indices and estimates of $N_{\mathrm{ef}}$ were larger in the pre-Act samples than the late post-Act samples (Table 1). However, a trend analysis of the proportion of haplotypes to sample size $(h / N)$ did not indicate a pattern of decaying genetic variation (Table $1, \chi^{2}=1.42, \quad P=$ $0.234)$, and pairwise- $\Phi_{\mathrm{ST}}$ values estimated from standard AMOVAs did not differ significantly from 0 (all $P>0.15$ ). Both results support the absence of population differentiation among temporal groups. Further, the overall topology of the haplotype networks did not change over our study period (Fig. 3). The pattern of stable cytochrome $b$ diversity during our 135-year study period was supported by the resampling analysis of the modern population. $H_{\mathrm{d}}$ point estimates from each temporal group overlapped with the $95 \% \mathrm{CI}$ of $H_{\mathrm{d}}$ estimated from the modern population, implying that individuals from each temporal group were likely to have been sampled from a global population with similar mtDNA variation to the modern population (Fig. 2).

\section{Demographic reconstruction}

Estimates of $\theta_{\mathrm{w}}$ were similar between the pre-Act and modern temporal groups for both the mtDNA control region and cytochrome $b$, implying no substantial change in $N_{\text {ef }}$ during our 135-year study period (Table 2). The estimates of $\theta_{\mathrm{w}}$ derived from cytochrome $b$ appeared to decline when only museum samples were included; the highest estimates of $N_{\mathrm{ef}}$ were for the Pre-Act group and the lowest estimates were for the Late Post-Act group (Table 2). However, $\theta_{\mathrm{w}}$ in the modern temporal group was not significantly different from any other temporal group, which does not support a decline in $N_{\text {ef }}$ during our 135-year study period.

We conducted a Bayesian Skyline reconstruction of trends in population size over our sampling period for cytochrome $b$ using the Tamura-Nei model of nucleotide substitution with invariable sites $(\mathrm{TrN}+\mathrm{I}$ model, base frequencies of $A=0.284, C=0.313, G=0.132, T=0.270$ ) and a relaxed lognormal clock (Tamura and Nei 1993). The resulting Bayesian Skyline plot supported a constant effective population size following the ban on market hunting, a result consistent with the temporal patterns of variation in our estimates of $N_{\text {ef }}$ (Fig. 4).
Fig. 4 Reconstruction of population fluctuations in the Buff-breasted Sandpiper based on a Bayesian skyline plot derived from cytochrome $b$ sequence data showing a stable population size over time. The solid black line represents the median estimate of effective population size and the solid gray lines represent the $95 \%$ CI. A grey box highlights the 50-year period during which Buff-breasted Sandpipers and other shorebirds were intensely commercially harvested in North America

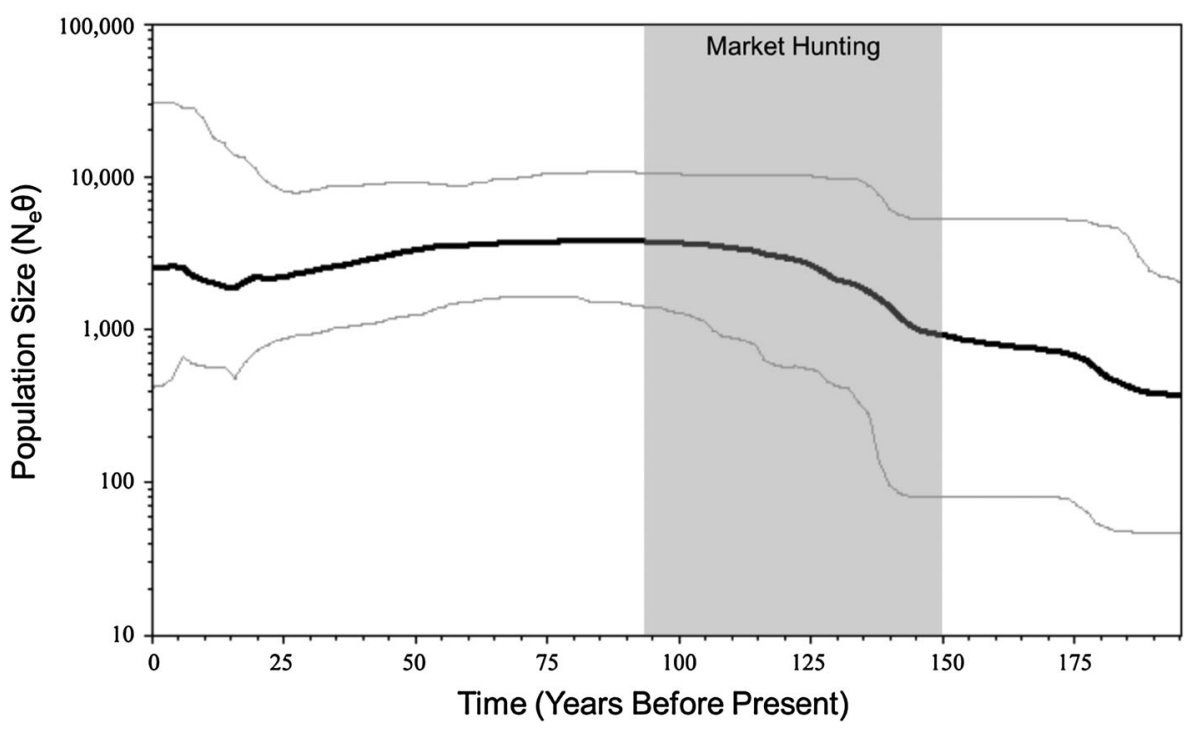




\section{Discussion}

The goal of our study was to assess how genetic variation changed within the global Buff-breasted Sandpiper population following a sudden, large-scale population decline at the turn of the 20th century and continuing gradual declines during the past century. We expected a decrease in mitochondrial DNA variation and effective population size of females following patterns found in other birds of conservation concern (Martinez-Cruz et al. 2007; Solovyeva and Pearce 2011; Draheim et al. 2012). Unexpectedly, we found little evidence of change in genetic variation when we compared several measures of mtDNA variation, $N_{\mathrm{ef}}$, and haplotype distributions over a 135 year time period that coincided with a series of reductions in population size. Most individuals from the historical samples exhibited one of two major haplotypes separated by a single mutation; this topological pattern was consistent with the pattern of haplotypes found in the modern population (Fig. 3, Lounsberry et al. 2013).

One important finding of this study was the sensitivity of diversity indices to sample size when overall diversity was low. Even at large sample sizes $(n=100)$, confidence limits of $H_{\mathrm{d}}$ calculated from the resampled populations were large and indicated that $H_{\mathrm{d}}$ could be greatly over- or under-estimated. Additionally, rarefaction analysis of haplotype proportions yielded large standard deviations. These findings emphasize the importance of cautious interpretation of trend data derived from small genetic datasets (e.g., from a sample relying heavily on museum collections). Despite a substantial sample size relative to other hDNA studies, metric sensitivity prompted us to use multiple independent techniques to adequately address our hypotheses. Studies that draw inference solely from diversity index estimates in small samples risk over- or underestimating haplotype diversity, and by proxy genetic variation, in historic populations. Also, conservation studies that use hDNA derived from museum specimens require an understanding of contemporary population genetic characteristics when selecting an adequate sample size to address their hypotheses. Our study, for example, was a unique case because a majority of contemporary individuals (approx. $75 \%$ ) had one of two major control region and cytochrome $b$ haplotypes, necessitating a larger sample size than a study system with more evenlydistributed haplotype frequencies (Lounsberry et al. 2013). When only a small number of historical samples (in our case $n<100)$ are available, it is advisable, when possible, to resample parameter estimates to understand how historical patterns of genetic variation affect the precision of those estimates. In addition, using a combination and variety of statistical and descriptive tools may further assist in understanding the consensus pattern of variation through time. Using multiple independent approaches to address our hypotheses, we feel our inferences are strongly supported.
For both the mtDNA control region and cytochrome $b$ gene in Buff-breasted Sandpipers, we observed patterns of stable variation and effective population size over the past 135 years. Multiple independent tests did not support the hypothesis that genetic variation declined over the course of the 20th century. These tests included a CochranArmitage test for a trend in haplotype proportions over time and multiple AMOVAs among temporal groups. Similarly, overlapping $95 \%$ confidence intervals for estimates of $\theta_{\mathrm{w}}$ as a proxy for effective population size, proportions of individuals with the most common haplotype, and rarefaction corrected haplotype richness indicated stable genetic variation and effective size. We supplemented the statistical evidence for no decline in genetic diversity by visualizing this pattern graphically in our haplotype networks and Bayesian Skyline plots. These results supported previous inferences made from mtDNA and microsatellite analyses of the contemporary population that no genetic bottleneck was detected. The results of multiple, independent statistical tests and descriptive tools for two mtDNA markers across both contemporary and historical populations allowed us to infer little or no decline in genetic variation in Buff-breasted Sandpipers during the 20th century.

While we expected to see a signal of declining genetic variation, other studies have also found mtDNA variation to be stable in species with declining populations (Brown et al. 2007; Kuro-o et al. 2010; Reding et al. 2010). In these species, high levels of mtDNA variation were likely maintained because historical populations had high genetic variation or large effective population sizes prior to declines and because populations recovered or stabilized quickly once these species were managed. Large populations are typically more resistant to the genetic effects of population reduction, and it is possible that a large population size prior to commercial harvest combined with concomitant high genetic variation, as well as legislation aimed at controlling market hunting, helped Buff-breasted Sandpipers retain genetic variation (Frankham et al. 2004). In addition, genetic variation may have been stabilized by certain natural history traits of this species, including a lack of breeding site fidelity which maintained a highly admixed global population, and a promiscuous mating pattern exhibited by females which promotes a more even reproductive output and large effective population size (Lanctot and Weatherhead 1997; Lanctot et al. 1997).

Here, we illustrated the utility of museum specimens for assessing trends in mtDNA variation within a declining population of migratory shorebirds. Our molecular analyses provided a historic perspective on the impact of anthropogenic disturbance on the future adaptability in Buff-breasted Sandpipers. Our results indicated that mtDNA variation and $N_{\text {ef }}$ have remained stable, and no 
evolutionarily distinct matrilines have been lost in Buffbreasted Sandpipers during the past 135 years. However, the failure to detect a loss of genetic variation in Buffbreasted Sandpipers does not indicate that active conservation or management actions are not warranted. Genetic variation is only one of multiple parameters used to determine population viability and does not fully address factors leading to demographic stochasticity as a mechanism of extinction. A limited number of studies suggest that Buff-breasted Sandpipers have been experiencing population declines, but a large pre-decline population size, global admixture, and the recentness of population declines could obscure a clear genetic signal (Lanctot et al. 2010). Indeed, genetic variation must always be interpreted in the context of population trends (e.g., reduction of population size, Gregory et al. 2011), which are mixed and largely unknown for this species.

The global loss and degradation of habitat essential to this species makes it vulnerable to extinction. To limit the impacts of demographic stochasticity and maintain robust populations of Buff-breasted Sandpipers, management recommendations outlined in the species conservation plan should be implemented (Lanctot et al. 2010). Specifically, birds that breed in the arctic need to be protected from the direct and indirect effects of oil and gas development, which is reducing habitat quality and potentially increasing predation rates (Liebezeit et al. 2009). Major stopover sites in the central U.S. need to be managed carefully to prevent further losses of suitable habitat and reduce chemical contamination (Jorgensen et al. 2008; Strum et al. 2010). Last, habitat degradation in winter sites across Brazil, Argentina, and Uruguay must be managed to limit possible habitat loss and population fragmentation (Almeida 2009). It is fortunate that this species has maintained genetic variability in the face of population losses, although pressures on the population are occurring globally and the population threshold at which genetic variation will be lost quickly is unknown (Lynch and Lande 1998).

\footnotetext{
Acknowledgments We thank the following people for their assistance with museum sampling efforts: B.K. Schmidt, Smithsonian Institution; C. Cicero, Museum of Vertebrate Zoology at University of California; J. Hinshaw, Museum of Zoology at University of Michigan; J. Trimble, Museum of Comparative Zoology at Harvard University; D. Easterla, Northwest Missouri State University; T. Yuri, Sam Noble Museum of Natural History at University of Oklahoma; J.L. Woods, Museum of Natural History at University of Delaware; T. Labedz, University of Nebraska and M. Robbins, Natural History Museum at University of Kansas. For modern samples, we thank the field crews and project leaders that helped with the major sampling efforts, specifically A. Leist, S. Kendall, C. T. Bernardo, G. S. Leal, M. S. Pereira, A. F. Pinto, F. Pöershke, U. B. Rasquin and H. A. Swensen; the ranch owners who allowed us access to their pastures, especially Sr. Dagoberto, Sr. Jorge, R. Bender and the "Manduca" Machado family; H.A. Almeida, C.S. Fontana as well as managers and staff of Parque Nacional da Lagoa do Peixe and
}

Estação Ecológica do Taim for logistic support; B. Streever at BP Exploration (Alaska), Inc. for assisting with field logistics at the Prudhoe Bay site; and S. Fellows and S. Jones from U.S. Fish and Wildlife Service for pursuing this study. H. Barton provided assistance with phylogeographic analyses, and colleagues in the Conservation Genetics and Molecular Ecology Lab at Kansas State University provided helpful feedback on earlier drafts of the manuscript. This project was funded by a grant from the U.S. Fish and Wildlife Service (Regions 6 \& 7). The findings and conclusions in this article are those of the author(s) and do not necessarily represent the views of the U.S. Fish and Wildlife Service.

Open Access This article is distributed under the terms of the Creative Commons Attribution License which permits any use, distribution, and reproduction in any medium, provided the original author(s) and the source are credited.

\section{References}

Allen JN (1980) The ecology and behavior of the Long-Billed Curlew in southern Washington. Wildl Monogr 73:3-67

Almeida J (2009) Wintering ecology of Buff-breasted Sandpipers (Tryngites subruficollis) in southern Brazil. PhD Dissertation, University of Nevada Reno, Reno

Andres BA, Smith PA, Morrison RIG, Gratto-Trevor CL, Brown SC, Friis CA (2012) Population estimates of North American shorebirds, 2012. Wader Study Group Bull 119:178-194

Armitage P (1955) Tests for linear trends in proportions and frequencies. Biometrics 11:375-386

Brook BW, Tonkyn DW, O'Grady JJ, Frankham R (2002) Contribution of inbreeding to extinction risk in threatened species. Conserv Ecol 6:16

Brown JW, Coeverden Van, de Groot PJ, Birt TP, Seutin G, Boag PT, Friesen VL (2007) Appraisal of the consequences of the DDTinduced bottleneck on the level and geographic distribution of neutral genetic variation in Canadian Peregrine Falcons, Falco peregrinus. Mol Ecol 16:327-343

Burleigh TD (1958) Georgia birds. University of Oklahoma, Norman

Butler RW, Ydenberg RC, Donaldson GD, and Brown S (2004) Hypotheses to explain census declines in North American shorebirds. Shorebird Research Group of the Americas Report 1. www.shorebirdresearch.org/workinggroups.htm. Accessed 01 May 2012

Clay RP, Lesterhuis AJ, and Johnson O (2010) Conservation Plan for the American Golden-Plover (Pluvialis dominica). Version 1.1. Manomet Center for Conservation Sciences, Manomet

Colwell RK (2009) EstimateS: statistical estimation of species richness and shared species from samples. Version 8.2. http:// purl.oclc.org/estimates. Accessed 01 May 2012

Draheim HM, Baird P, Haig SM (2012) Temporal analysis of mtDNA variation reveals decreased genetic diversity in Least Terns. Condor 114:145-154

Drummond AJ, Rambaut A (2007) BEAST: Bayesian evolutionary analysis by sampling trees. BMC Evol Biol 7:214

Excoffier L, Laval G, Schneider S (2005) Arlequin ver. 3.0: an integrated software package for population genetics data analysis. Evol Bioinform Online 1:47-50

Frankham R (2005) Genetics and extinction. Biol Conserv 126:131-140

Frankham R, Ballou JD, Briscoe DA (2004) A primer of conservation genetics. Cambridge University Press, Cambridge

George RC (2002) Reproductive ecology of the American Oystercatcher (Haematopus palliatus) in Georgia. M.Sc thesis, University of Georgia, Athens 
Graves GR (2010) Late 19th century abundance trends of the Eskimo Curlew on Nantucket Island, Massachusetts. Waterbirds 33:236-241

Gregory AJ, Kaler RSA, Prebyl TJ, Sandercock BK, Wisely SM (2011) Influence of translocation strategy and mating system on the genetic structure of a newly established population of island ptarmigan. Conserv Genet 13:465-474

Hall TA (1999) BioEdit: a user-friendly biological sequence alignment editor and analysis program for Windows 95/98/NT. Nucleic Acids Symp 41:95-98

Johnson JA, Dunn PO, Bouzat JL (2007) Effects of recent population bottlenecks on reconstructing the demographic history of prairiechickens. Mol Ecol 16:2203-2222

Jorgensen JG, McCarty JP, Wolfenbarger LL (2008) Buff-breasted Sandpiper density and numbers during migratory stopover in the Rainwater Basin, Nebraska. Condor 110:63-69

Kuro-o M, Yonekawa H, Saito S, Eda M, Higuchi H, Koike H, Hawegaway H (2010) Unexpectedly high genetic variation of mtDNA control region through severe bottleneck in vulnerable albatross Phoebastria albatrus. Conserv Genet 11:127-137

Lanctot RB, Laredo CD (1994) Buff-breasted Sandpiper (Tryngites subruficollis). Birds of North America, No. 91. Philadelphia, Pennsylvania, USA

Lanctot RB, Weatherhead PJ (1997) Ephemeral lekking behavior in the Buff-breasted Sandpiper, Tryngites subruficollis. Behav Ecol 8:268-278

Lanctot RB, Scribner BK, Kempenaers B, Weatherhead PJ (1997) Lekking without a paradox in the Buff-breasted Sandpiper. Am Nat 149:1051-1070

Lanctot RB, Aldabe J, Almeida JB, Blanco D, Isacch JP, Jorgensen J, Norland S, Rocca P, and Strum KM (2010) Conservation Plan for the Buff-breasted Sandpiper (Tryngites subruficollis).Version 1.1. U. S. Fish and Wildlife Service, Anchorage, Alaska, and Manomet Center for Conservation Sciences, Manomet, Massachusetts, USA

Librado P, Rosaz J (2009) DnaSP v5: a software for comprehensive analysis of DNA polymorphism data. Bioinformatics 25:14511452

Liebezeit JR, Kendall SJ, Brown S, Johnson CB, Martin P, McDonald TL, Payer DC, Rea CL, Streever B, Wildman AM, Zack S (2009) Influence of human development and predators on nest survival of tundra birds, Arctic Coastal Plain, Alaska. Ecol Appl 19:1628-1644

Lounsberry ZL, Almeida JB, Grace T, Lanctot RB, Liebezeit J, Sandercock BK, Strum KM, Zack S, Wisely SM (2013) Rangewide conservation genetics of Buff-breasted Sandpipers (Tryngites subruficollis). Auk 130:429-439

Lynch M, Lande R (1998) The critical effective size for a genetically secure population. Anim Conserv 1:70-72

Martinez-Cruz B, Godoy JA, Negro JJ (2007) Population fragmentation leads to spatial and temporal genetic structure in the endangered Spanish imperial eagle. Mol Ecol 16:477-486

McIlhenny EA (1943) Major changes in the bird life of southern Louisiana during 60 years. Auk 60:541-549

Millar CD, Huynen L, Subramanian S, Mohandesan E, Lambert DM (2008) New developments in ancient genomics. Trends Ecol Evol 23:386-393

Morrison RIG, McCaffery BJ, Gill RE, Skagen SK, Jones SL, Page GW, Gratto-Trevor CL, Andres BA (2006) Population estimates of North American shorebirds. Wader Study Group Bull 111: $67-85$

Mourier T, Ho SYW, Gilbert MTP, Willerslev E, Orlando L (2012) Statistical guidelines for detecting past population shifts using ancient DNA. Mol Biol Evol 29:2241-2251
Myers JP (1980) Territoriality and flocking by Buff-breasted Sandpipers: variations in non-breeding dispersion. Condor $82: 241-250$

Norling W, Jeske CW, Thigpen TF, Chadwick PC (2012) Estimating shorebird populations during spring stopover in rice fields of Louisiana and Texas Gulf Coastal Plain. Waterbirds 35:361-370

Palsbøll PJ, Peery MZ, Olsen MT, Beissinger SR, Bérubé M (2013) Inferring recent historic abundance from current genetic diversity. Mol Ecol 22:22-40

Posada D (2008) jModelTest: phylogenetic model averaging. Mol Biol Evol 25:1253-1256

Prost S, Anderson CNK (2011) TempNet: a method to display statistical parsimony networks for heterochronous DNA sequence data. Methods Ecol Evol 2:663-667

R Development Core Team (2010) R: A language and environment for statistical computing. R Foundation for Statistical Computing, Vienna

Ramakrishnan U, Hadly EA (2009) Using phylochronology to reveal cryptic population histories: review and synthesis of 29 ancient DNA studies. Mol Ecol 18:1310-1330

Reding DM, Freed LA, Cann RL, Fleischer RC (2010) Spatial and temporal patterns of genetic variation in an endangered Hawaiian honeycreeper, the Hawaii Akepa (Loxops coccineus coccineus). Conserv Genet 11:225-240

Roberts D, Elphick CS, Reed MJ (2009) Identifying anomalous reports of putatively extinct species and why it matters. Conserv Biol 24:189-196

Rodríguez F, Albornoz J, Domínguez A (2007) Cytochrome $b$ pseudogene originated from a highly divergent mitochondrial lineage in genus Rupicapra. J Hered 98:243-249

Rowan W (1927) Notes on Alberta waders included in the British list. Part V. Tryngites subruficollis, Buff-breasted Sandpiper. $\mathrm{Br}$ Birds 20:186-192

Solovyeva DV, Pearce JM (2011) Comparative mitochondrial genetics of North American and Eurasian mergansers with an emphasis on the endangered Scaly-sided Merganser (Mergus squamatus). Conserv Genet 12:839-844

Soulé ME (1991) Conservation: tactics for a constant crisis. Science 253:744-750

Spielman D, Brook BW, Frankham R (2004) Most species are not driven to extinction before genetic factors impact them. Proc Natl Acad Sci 101:15261-15264

Strum KM, Hooper MJ, Johnson KA, Lanctot RB, Zaccagnini ME, Sandercock BK (2010) Exposure of nonbreeding migratory shorebirds to cholinesterase-inhibiting contaminants in the Western Hemisphere. Condor 112:15-28

Sutherland WJ, Alves JA, Amano T, Chang CH, Davidson NC, Finlayson CM, Gill JA, Gill RE, González PM, Gunnarsson TG, Kleijn D, Spray CJ, Székely T, and Thompson DBA (2012) A horizon scanning assessment of current and potential future threats to migratory shorebirds. Ibis 154:663-679

Tamura K, Nei M (1993) Estimation of the number of nucleotide substitutions in the control region of mitochondrial DNA in humans and chimpanzees. Molecular Biology and Evolution 10:512-526

Tamura K, Dudley J, Nei M, Kumar S (2007) MEGA4: molecular evolutionary genetics analysis (MEGA) software version 4.0. Mol Biol Evol 24:1596-1599

Tudor L (2000) Migratory shorebird assessment. Maine Department of Inland Fisheries and Wildlife, Resource Assessment Section, Bird Group, Bangor

Wandeler P, Hoeck PEA, Keller LF (2007) Back to the future: museum specimens in population genetics. Trends Ecol Evol 22:634-642

Weik AP (2001) Woodcock assessment. Maine Department of Inland Fisheries and Wildlife, Bangor 
Westemeier RL, Brawn JD, Simpson SA, Esker TL, Jansen RW, Walk JW, Kershner EL, Bouzat JL, Paige BKN (1998) Tracking the long-term decline and recovery of an isolated population. Science 282:1695-1698

Wetmore A (1927) Our migrant shorebirds in Southern South America. U.S.D.I. Tech. Bull. No. 26, Washington, DC
Wisely SM, Maldonado JE, Fleischer RC (2004) A technique for sampling ancient DNA that minimizes damage to museum specimens. Conserv Genet 5:105-107

Zar JH (1984) Biostatistical analysis, 2nd edn. Prentice-Hall Inc, Englewood Cliffs 